\title{
Postoperative expression of Cushing disease in a young male: metamorphosis of silent corticotroph adenoma?
}

\author{
Sharmin Jahan11, M A Hasanat1', Tahseen Mahmood1', Shahed Morshed¹, Raziul Haq² and \\ Md Fariduddin'
}

1Department of Endocrinology, Bangabandhu Sheikh Mujib Medical University (BSMMU), Dhaka, Bangladesh and 2Department of Neurosurgery, Dhaka Medical College and Hospital (DMCH), Dhaka, Bangladesh
Correspondence should be addressed to S Jahan

Email

sharmindmc1975@gmail.com

\begin{abstract}
Summary
Silent corticotroph adenoma (SCA) is an unusual type of nonfunctioning pituitary adenoma (NFA) that is silent both clinically and biochemically and can only be recognized by positive immunostaining for ACTH. Under rare circumstances, it can transform into hormonally active disease presenting with severe Cushing syndrome. It might often produce diagnostic dilemma with difficult management issue if not thoroughly investigated and subtyped accordingly following surgery. Here, we present a 21-year-old male who initially underwent pituitary adenomectomy for presumed NFA with compressive symptoms. However, he developed recurrent and invasive macroadenoma with severe clinical as well as biochemical hypercortisolism during post-surgical follow-up. Repeat pituitary surgery was carried out urgently as there was significant optic chiasmal compression. Immunohistochemical analysis of the tumor tissue obtained on repeat surgery proved it to be an aggressive corticotroph adenoma. Though not cured, he showed marked clinical and biochemical improvement in the immediate postoperative period. Anticipating recurrence from the residual tumor, we referred him for cyber knife radio surgery.
\end{abstract}

\section{Learning points:}

- Pituitary NFA commonly present with compressive symptoms such as headache and blurred vision.

- Post-surgical development of Cushing syndrome in such a case could be either drug induced or endogenous.

- In the presence of recurrent pituitary tumor, ACTH-dependent Cushing syndrome indicates CD.

- Rarely a SCA presenting initially as NFA can transform into an active corticotroph adenoma.

- Immunohistochemical marker for ACTH in the resected tumor confirms the diagnosis.

\section{Background}

The silent corticotroph adenoma (SCA) represents an uncommon subset of nonfunctioning pituitary adenomas (NFAs). It was first reported by Kovacs et al. in 1978 and further defined by Horvath et al. in 1980 $(1,2)$. This subpopulation of NFA is characterized by a lack of hypercortisolemia, no clinical evidence of Cushing disease $(\mathrm{CD})$, and positive immunostaining for adrenocorticotropic hormone (ACTH) (3). These distinct subtypes of pituitary adenomas represent approximately
$20 \%$ of all corticotroph adenomas and approximately 5\% (3-19\% depending on series) of NFAs (4). These are usually macroadenoma and tend to have a more aggressive presentation with a higher chance of hemorrhage and invasion of anatomical structures (5). SCA patients are younger than the patients with ACTH-negative NFAs (6). Transformation of SCA into active CD though rare yet has been reported in the literature. Here in we report a young male undergoing pituitary surgery for a presumed 
NFA who later developed severe Cushing syndrome. Ultimately he was proven to have SCA that surprisingly became hormonally active during post-surgical period. On repeat surgery, diagnosis was confirmed by positive immunostaining for ACTH.

\section{Case presentation}

A 21-year-old non-alcoholic, non-smoker male presented with progressive weight gain. Three years back he was evaluated for gradual visual disturbance with narrowing of the visual field and discovered to have pituitary macroadenoma (Fig. 1A). It was not associated with headache, nausea, vomiting, and diplopia and there were no clinical features suggestive of hormonal hypersecretion or hypopituitarism (Fig. 2A). Hormonal investigations were unremarkable (Table 1), and he was diagnosed as a case of nonfunctioning pituitary macroadenoma. There was no family history suggestive of any pituitary tumor or genetic syndrome associated with adrenal tumor. Following that he underwent trans-sphenoidal adenomectomy (TSA) and post-surgical histopathology revealed pituitary adenoma. However, immunohistochemical study was not done on that instance. In the peri-operative period he received oral dexamethasone for 3 weeks. His visual disturbance did not completely improve and for that he took various types of steroid containing medications on and off for 1 year. Soon after the operation, he noticed progressive weight gain and appearance of purplish striae over the abdomen. As his visual complaint remained unchanged he stopped these medications abruptly. At that time he did not develop any adrenal crisis and his weight remained static and the striae turned white. However, for the last 2 years he had been off any medication. Even so, he started gaining considerable weight with reappearance of purple striae and gradual deterioration of vision.
These complaints led to his admission into our hospital. He was an obese gentle man (BMI $33 \mathrm{~kg} / \mathrm{m}^{2}$ ), having moon face with plethora. There was prominent central obesity, acanthosis nigricans, dorsocervical fat pad and supraclavicular fullness. There were wide, depressed redpurple striae over lower abdomen (Fig. 2B) and widespread fungal infection in extremities. His BP was $140 / 100 \mathrm{mmHg}$ without any postural drop. Ophthalmologic examination showed diminished visual acuity (right eye 6/12, left eye counting finger), global restriction of visual field on confrontation and fundoscopy showed pallor in both discs with unremarkable macula. At this point we were in favor of nonfunctioning pituitary macroadenoma (postsurgical state) with drug-induced Cushing syndrome.

\section{Investigation}

Routine hematologic and biochemical investigations showed neutrophilic leukocytosis, elevated liver enzyme, impaired fasting and post-glucose values and evidence of combined dyslipidemia. Other tests including serum creatinine, BUN, and electrolytes were all normal. Then we embarked on the hormonal investigations. He had low serum prolactin and hypogonadotropic hypogonadism with normal thyroidal axis (Table 1). Plasma basal cortisol and ACTH were found to be significantly high on several occasions, and 24-h-urinary free cortisol was found to be moderately elevated twice and normal once. So, to confirm Cushing syndrome we performed overnight low-dose dexamethasone suppression test (LDDST) which was also done previously at another center. The plasma cortisol remained unsuppressed both the times confirming Cushing syndrome (Table 2). At this point the drug-induced Cushing was virtually excluded because he was off the offending drugs for last 2 years and both plasma cortisol and ACTH were found to be high rather
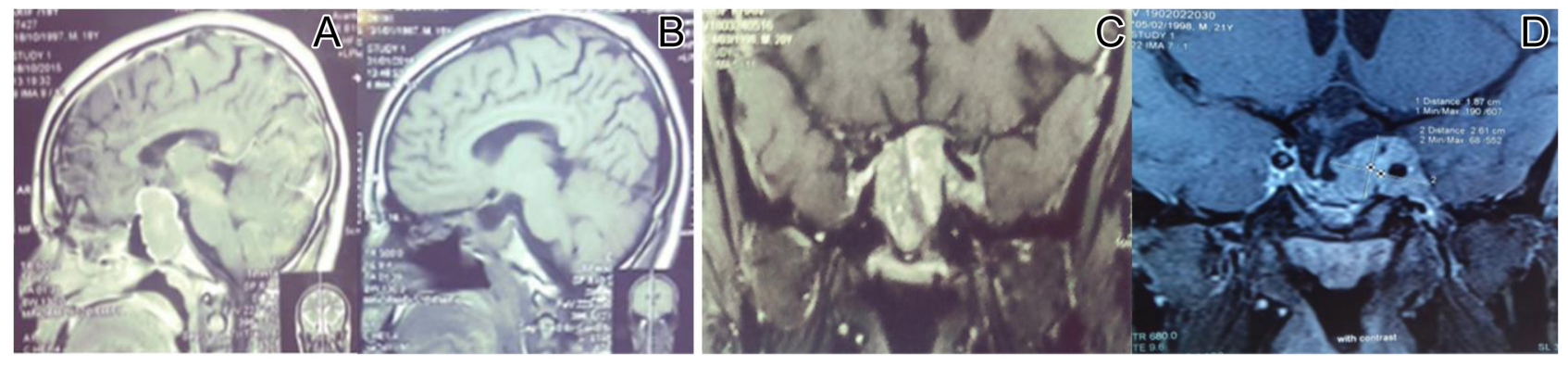

\section{Figure 1}

MRI of pituitary macroadenoma in relation with surgery. (A) Before 1st operation (sellar mass with suprasellar extension); (B) after 1st operation (residual sellar mass with postoperative fluid collection); (C) before 2 nd operation (recurrence of the tumor); (D) after 2 nd operation (partial empty sella with residual mass). 

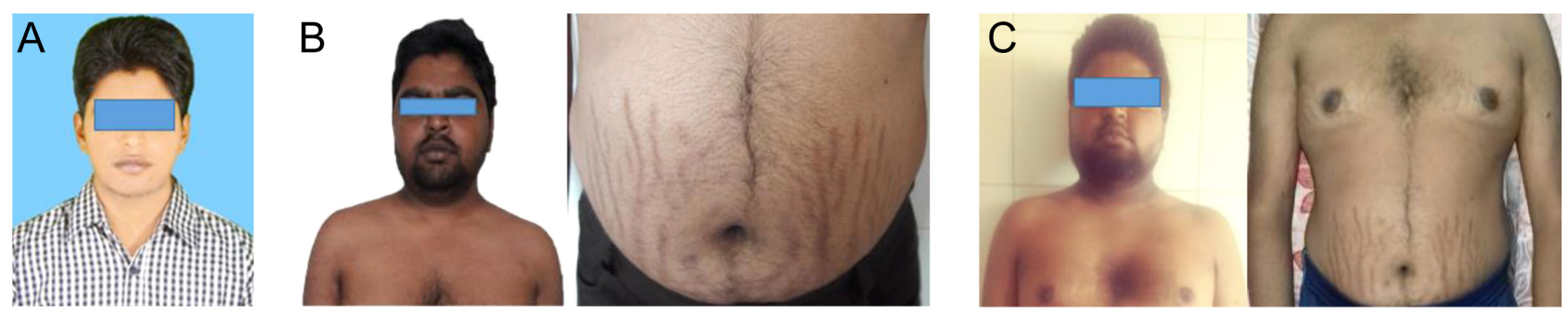

Figure 2

Facial appearance and abdominal striae of the patient. (A) Before first surgery (normal); (B) before second surgery (Cushingoid); (C) 1 month after second surgery (regression of Cushingoid appearance).

low. So he represented a case of endogenous Cushing syndrome. To find out the etiology we repeated plasma ACTH and it was reasonably high rendering him an ACTHdependent Cushing syndrome. Plasma cortisol remained $>90 \%$ of baseline level following overnight high-dose dexamethasone suppression test (HDDST) which raised the possibility of ectopic Cushing syndrome (Table 2). For localization he underwent HRCT of chest and abdomen and both were unremarkable. Then we reviewed our provisional diagnosis and CD seemed to be a possibility. We consulted a neurosurgeon as he had recurrence of the previous tumor with compression on the optic chiasm (Fig. 1C) that necessitated urgent decompression.

\section{Treatment}

After consultation with the neurosurgeon our patient immediately underwent repeat pituitary surgery. Few days later the histopathology and immunohistochemistry reports were available. It was positive for ACTH and FSH immunostaining and for reticulin fibers as well as CAM 5.2
(Fig. 3A, B, C and D). So our final diagnosis was SCA that underwent post-surgical transformation into active $\mathrm{CD}$.

\section{Outcome and follow-up}

One month later he came on regular follow-up. He had made significant subjective and objective improvement (Fig. 2C). His weight had reduced from 85 to $75 \mathrm{~kg}$, his $\mathrm{BP}$ was $100 / 80 \mathrm{mmHg}$ without medication, his vision also improved to greater extent and the striae were turning whitish (Fig. 2C). There was also significant biochemical improvement (Table 1) and post-surgical MRI showed small residual tumor (Fig. 1D). Anticipating the aggressive behavior of the tumor he underwent radiation therapy with cyber knife radiosurgery.

\section{Discussion}

SCAs are clinically nonfunctioning pituitary adenomas (NFAs) with a positive staining for adrenocorticotropic hormone $(\mathrm{ACTH})$ on immunohistochemistry $(7,8)$.

Table 1 Hormone profile of the patient in relation to pituitary surgery.

\begin{tabular}{|c|c|c|c|c|}
\hline \multirow[b]{2}{*}{ Hormone profile } & \multicolumn{3}{|c|}{ Results } & \multirow[b]{2}{*}{ Reference value } \\
\hline & Before first surgery & After first surgery & After second surgery & \\
\hline \multicolumn{5}{|l|}{ Adrenal axis } \\
\hline Basal cortisol & $15.34 \mu \mathrm{g} / \mathrm{dL}$ & & $583.2 \mathrm{nmol} / \mathrm{L}$ & $5-25 \mu \mathrm{g} / \mathrm{dL}$ \\
\hline 1 st instance & & $1328 \mathrm{nmol} / \mathrm{L}$ & & \\
\hline 2nd instance & & $923.2 \mathrm{nmol} / \mathrm{L}$ & & $138-690 \mathrm{nmol} / \mathrm{L}$ \\
\hline Plasma ACTH (pg/mL) & Not done & & 239 & Undetectable - 46 \\
\hline 1st instance & & 173 & & \\
\hline 2nd instance & & 153.8 & & \\
\hline \multicolumn{5}{|l|}{ Thyroid axis } \\
\hline Serum TSH ( $\mu \mathrm{IU} / \mathrm{mL})$ & 2.21 & 1.29 & Not done & $0.35-5.5$ \\
\hline Serum FT4 (ng/dL) & 1.27 & 1.25 & Not done & $0.8-1.8$ \\
\hline \multicolumn{5}{|l|}{ Gonadal axis } \\
\hline Serum LH (mIU/mL) & Not done & 3.93 & 4.67 & $0.8-7.8$ \\
\hline Serum FSH (mIU/mL) & Not done & 1.8 & 6.39 & $0.7-11.1$ \\
\hline Serum testosterone (ng/dL) & Not done & 152.5 & Not done & $270-1734$ \\
\hline Serum prolactin $(\mathrm{ng} / \mathrm{mL})$ & 6.4 & 3.1 & Not done & $2.2-8.5$ \\
\hline
\end{tabular}


Table 2 Evaluation of Cushing syndrome during subsequent recurrence.

\begin{tabular}{|c|c|c|}
\hline Tests & Results & Reference value \\
\hline 24-h urinary free cortisol ( $\mu \mathrm{g} / 24 \mathrm{~h})$ & & $50-190$ \\
\hline 1st instance & 242 & \\
\hline 2nd instance & 267 & \\
\hline Serum cortisol after LDDST (nmol/L) & 686.7 & $<50$ \\
\hline Basal cortisol (nmol/L) & 1328 & $138-690$ \\
\hline Serum cortisol after HDDST (nmol/L) & 847.5 & \\
\hline
\end{tabular}

HDDST, high-dose dexamethasone suppression test; LDDST, low-dose dexamethasone suppression test.

These adenomas do not exhibit any clinical or biochemical evidence of $\mathrm{CD}$. The exact incidence rate of SCAs is unknown, which is reported to vary from $9 \%$ to $32.7 \%$ (3). Before surgery, they present in an identical way to NFAs, with clinical features suggesting a local mass effect, including headache, visual field defects, and hypopituitarism (9). The definitive diagnosis of SCA is determined retrospectively after pathologic examination of the resected tumor tissue (4). Although the preoperative features are similar to those of other NFAs, SCAs tend to have a more aggressive postoperative course $(6,10)$. Some studies have demonstrated that SCAs recur earlier, and de novo or multiple recurrences were observed more frequently compared with other NFAs $(11,12)$. There have been rare instances where an initial SCA transformed into functional corticotroph adenoma following surgery or radiotherapy. In these cases, the exact mechanism behind initial clinical silence or later activation is still speculative.

SCAs are different from CD in a sense that they are clinically and hormonally inactive. Commonly they are aggressive macroadenoma in contrast to the predominance of microadenoma in the latter. As a result they are included in the NFA categories that are diagnosed on the basis of immunohistochemical staining. Initially such tumor presents with mass effect like headache, vomiting or visual disturbance. However, there are certain characteristics that alert a clinician toward the diagnosis. The patient in our scenario was a young male presented with compressive symptoms of a large pituitary tumor that had no clinical or biochemical activity. Shortly after undergoing TSA he developed aggressive CD with very high ACTH and nonsuppressed HPA axis even on HDDST. Considering the straightforward clinical picture, immunohistochemistry was not advised at the initial operation. Therefore, we were at a diagnostic dilemma between CD and ectopic Cushing syndrome on readmission. Imaging studies failed to localize ectopic ACTH-secreting tumor but showed early recurrence of invasive pituitary tumor with optic nerve compression demanding immediate TSA. Positive post-surgical immunohistochemical marker of the tumor for ACTH along with significant clinical and biochemical improvement led to the ultimate diagnosis.

Though the lack of clinical manifestations of hypercortisolism in patients with SCA is well documented in the literature, the pathogenesis still remains unclear. Various mechanisms for the clinical silence of these tumors have been postulated and include, but are not limited to: biological inactivity of ACTH, increase in intracellular disposal by lysosomes, defective packaging of ACTH into secretory granules due to an inadequately developed Golgi complex and failure of exocytosis of hormone from the cell membrane $(9,10)$. In a study by Gibson et al. it has been found that ACTH may be functionally inactive because of abnormal processing of POMC (13). SCAs have also been found to have lower expressions of proconvertase $1 / 3$ (PC1/3), which is the enzyme that is responsible for cleaving POMC into ACTH $(14,15)$. Translational or post-translational abnormalities of ACTH have been suggested in SCAs (16). Despite the absence of clinical hypercortisolism in patients with SCAs, elevated plasma ACTH levels are observed. Therefore, some SCAs have been reported to secrete mostly biologically inactive, high-molecular-weight ACTH which can be detected on gel chromatography (17). In our patient the hormonal measurements were done by immuno-chemiluminescent assay rather than gel chromatography. So it is difficult to comment whether this method was unable to pick up the bio inactive, large ACTH molecules in the presumed NFA state or whether it was truly non-secretory in nature in the initial stage.
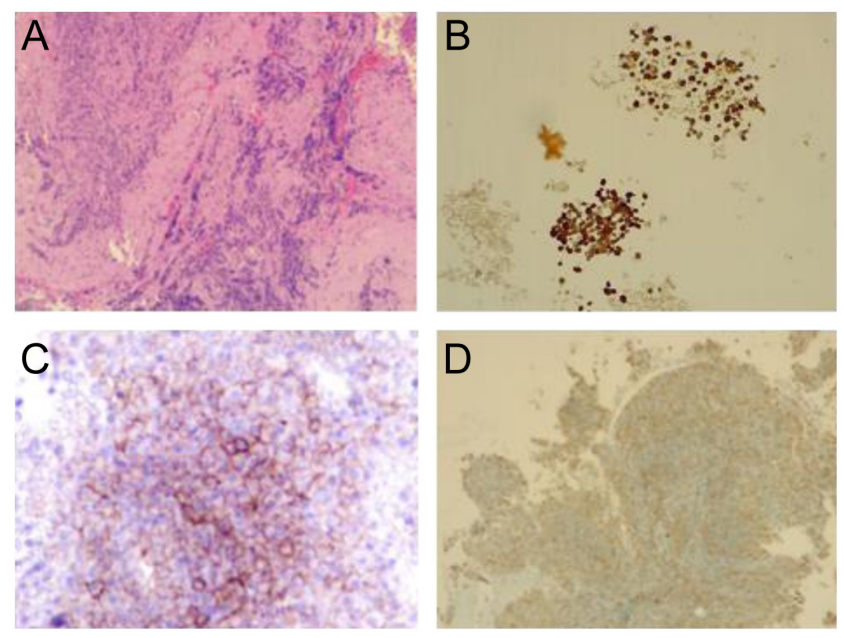

Figure 3

Photomicrographs of the pituitary adenoma showing (A) PAS stain; immunopositivity for (B) FSH (4+) (C) BER EP 4 (EP 155) and (D) ACTH (2+). 
Kim et al. reported one SCA case showing transformation into biochemical CD after surgery. That patient had no clinical or biochemical evidence of CD at presentation. She also had normal 24-h urinaryfree cortisol levels before and after surgery. However, approximately 2 months later, her basal ACTH and 24-h urinary free cortisol were elevated, and she was diagnosed with biochemical CD (18). Righi et al. studied 132 cases of CD and 44 SCA from 1998 to 2013. During follow-up, three patients with SCA showed a clear transformation from SCA into CD and underwent surgery once again to remove the recurrent tumors. The PC1/3 expression was analyzed by both immunohistochemistry and quantitative real time-polymerase chain reaction (qRT-PCR) in primary and recurrent tumors. The immunohistochemical PC1/3 expression was negative or weak in the three patients in the initial phase of SCA, while a strong expression was observed in the majority of neoplastic cells in tissue specimens obtained from the same three patients at the time of recurrence as CD. The immunohistochemical PC1/3 expression showed a strict correlation with the PC1/3 levels obtained by qRT-PCR. Their study provided insight into the crucial role of the $\mathrm{PC} 1 / 3$ protein in the transformation of phenotype from SCA to CD (19). SCAs might as well be considered as less differentiated corticotropinoma. T-pit is an essential transcription factor for POMC transcription and corticotroph differentiation (20), and both T-pit and POMC expression levels are lower in SCAs (13). SCAs differentiate from overt or subclinical CD in terms of hormonal and molecular behaviors (20). SCAs exhibit different levels of corticotroph differentiation with some being poorly differentiated corticotroph tumors (20). In fact, in addition to corticotroph features, SCAs were shown to incorporate gonadotroph elements as evidenced by the presence of honeycomb Golgi or transcriptional factors (21). The immunohistochemical marker for FSH was strongly positive in our patient supporting incorporation of gonadotrophin element.

Two distinct pathologic subtypes of SCAs are recognized (9). Macroscopically, both SCA subtypes are generally macroadenomas with variable invasion or compression of parasellar structures. This is in stark contrast to functional ACTH adenomas, which are mostly found to be microadenomas at the time of clinical presentation due to the manifestations of hypercortisolemia. Type I SCA, which accounts for 68\%, is histologically and ultrastructurally indistinguishable from classical Cushing adenoma with the exception of having the crooke's hyaline changes, which are pathognomonic for $\mathrm{CD}$ as a result of persistent hypercotisolemia. These type I tumors show strong ACTH expression by the majority of tumor cells. In contrast, the type II SCA has only patchy or faint ACTH positivity by immunohistochemistry (9). Our patient probably had type II SCA with patchy ACTH activity and interestingly it stained positive for $\mathrm{FSH}$ indicating pleurihormonal nature.

Historically, SCA is considered an aggressive tumor characterized by a biological behavior between that of (ACTH-negative) NFA and adenomas causing CD $(8,9$, $10,11,20,21,22)$, the recurrence of or progression of residual tumor in patients with an NFA after microsurgical resection vary, depending upon the extent of resection. A recurrence rate of $10-25 \%$ was reported in patients in whom a gross total resection was achieved, whereas it was as high as $50 \%$ in patients who underwent a subtotal resection $(23,24,25)$.

SCAs are a more aggressive tumor with earlier recurrence than other NFAs. The patient in our case scenario had early postoperative recurrence with an ugly looking invasive macroadenoma impinging the optic chiasm. There have been no distinguishable clinical parameters available for the early identification of SCAs before surgery. Although recurrence of NFAs is reportedly associated with elevated Ki-67 and TUNEL indexes, no significant increase in the Ki-67 index was noted in recurrences by some authors (26). Though our patient presented with aggressive pituitary tumor yet his Ki-67 index was found to be low, only 1-2\% supporting previous literature. Because of the high risk of recurrence for SCAs, treatment for those patients experiencing a recurrence or progression includes reoperation, conventional RT, and SRS (9, 10, 20, 22, 27). However, a rare case was reported in which a SCA developed into $\mathrm{CD}$ following surgery that suggested being a potential indicator for future malignant behavior (28). Alahmadi et al. reported two recurrent cases who had a relatively high MIB-1 score and recommended reserving adjuvant radiotherapy (radiation) for the subset of SCAs that demonstrate more aggressive clinical behavior on close surveillance MRI or having a higher MIB-1 labeling index (29). Other predictors should be established in the future. Temozolomide can be used as an alternative treatment for SCAs when conventional therapy such as reoperation and radiotherapy are ineffective. It is based on the fact that a subset of aggressive pituitary adenomas and carcinomas respond well to the second-generation alkylating agent temozolomide (30). As SCA patients are typically young with a high incidence of postoperative tumor regrowth, long-term follow-up is necessary. 
Appropriate biochemical and immunohistochemical subtyping of a NFA can often pick up SCA which in rare instances can transform into a hormonally active tumor thereby producing challenge to diagnosis and future management.

\section{Declaration of interest}

The authors declare that there is no conflict of interest that could be perceived as prejudicing the impartiality of the research reported.

\section{Funding}

Fund was provided by the investigators themselves.

\section{Patient consent}

Written informed consent was obtained from the patient for publication of the submitted article and the accompanying images.

\section{Author contribution statement}

The clinical and biochemical part of the research was carried out by the investigators of BSMMU, Dhaka and surgical management was done by Department of Neurosurgery, DMCH. The script was prepared mostly by $\mathrm{Dr}$ Sharmin Jahan, while others helped in history taking, physical examination, planning and executing the investigations. All the authors read and approved the draft.

\section{References}

1 Kovacs K, Horvath E, Bayley TA, Hassaram ST \& Ezrin C. Silent corticotroph cell adenoma with lysosomal accumulation and crinophagy. A distinct clinicopathologic entity. American Journal of Medicine 197864 492-499. (https://doi.org/10.1016/00029343(78)90236-x)

2 Horvath E, Kovacs K, Killinger DW, Smyth HS, Platts ME \& Singer W. Silent corticotropic adenomas of the human pituitary gland: a histologic, immunocytologic, and ultrastructural study. American Journal of Pathology 198098 617-638.

3 Young Jr WF. Clinically nonfunctioning pituitary adenomas. In Diagnosis and Management of Pituitary Tumors, pp 343-351. Eds K Thapar, K Kovacs, BW Scheithauer \& RV Lloyd. Totowa, NJ: Humana Press, 2001

4 Ben-Shlomo A \& Cooper O. Silent corticotroph adenomas. Pituitary 201821 183-193. (https://doi.org/10.1007/s11102-018-0864-8)

5 Alahmadi H, Lee D, Wilson JR, Hayhurst C, Mete O, Gentili F, Asa SL $\&$ Zadeh G. Clinical features of silent corticotroph adenomas. Acta Neurochirurgica 2012154 1493-1498. (https://doi.org/10.1007/ s00701-012-1378-1)

6 Ioachimescu AG, Eiland L, Chhabra VS, Mastrogianakis GM, Schniederjan MJ, Brat D, Pileggi AV \& Oyesiku NM. Silent corticotrophadenomas: Emory University cohort and comparison with ACTH-negative nonfunctioning pituitary adenomas. Neurosurgery 201271 296-303; discussion 304. (https://doi. org/10.1227/NEU.0b013e318257c1f0)

7 Lopez JA, Kleinschmidt-Demasters BK, Sze CI, Woodmansee WW $\&$ Lillehei KO. Silent corticotroph adenomas: further clinical and pathological observations. Human Pathology 200435 1137-1147. (https://doi.org/10.1016/j.humpath.2004.04.016)

8 Cho HY, Cho SW, Kim SW, Shin CS, Park KS \& Kim SY. Silent corticotroph adenomas have unique recurrence characteristics compared with other nonfunctioning pituitary adenomas. Clinical Endocrinology 201072 648-653. (https://doi.org/10.1111/j.13652265.2009.03673.x)

9 Scheithauer BW, Jaap AJ, Horvath E, Kovacs K, Lloyd RV, Meyer FB, Laws Jr ER \& Young Jr WF. Clinically silent corticotroph tumors of the pituitary gland. Neurosurgery 200047 723-729; discussion 729. (https://doi.org/10.1097/00006123-200009000-00039)

10 Jahangiri A, Wagner JR, Pekmezci M, Hiniker A, Chang EF, Kunwar S, Blevins L \& Aghi MK. A comprehensive long-term retrospective analysis of silent corticotrophic adenomas vs. hormone-negative adenomas. Neurosurgery 201373 8-17; discussion 17. (https://doi. org/10.1227/01.neu.0000429858.96652.1e)

11 Cooper O, Ben-Shlomo A, Bonert V, Bannykh S, Mirocha J \& Melmed S. Silent corticogonadotrophadenomas: clinical and cellular characteristics and long-term outcomes. Hormones and Cancer $2010 \mathbf{1}$ 80-92. (https://doi.org/10.1007/s12672-010-0014-x)

12 Baldeweg SE, Pollock JR, Powell M \& Ahlquist J. A spectrum of behaviour in silent corticotroph pituitary adenomas. British Journal of Neurosurgery 200519 38-42. (https://doi. org/10.1080/02688690500081230)

13 Gibson S, Ray DW, Crosby SR, Dornan TL, Jennings AM, Bevan JS, Davis JRE \& White A. Impaired processing of proopiomelanocortin in corticotroph macroadenomas. Journal of Clinical Endocrinology and Metabolism 199681 497-502. (https://doi.org/10.1210/ jcem.81.2.8636257)

14 Ohta S, Nishizawa S, Oki Y, Yokoyama T \& Namba H. Significance of absent prohormoneconvertase $1 / 3$ in inducing clinically silent corticotroph pituitary adenoma of subtype I immunohistochemical study. Pituitary 20025 221-223. (https://doi. org/10.1023/A:1025321731790)

15 Tateno T, Izumiyama H, Doi M, Akashi T, Ohno K \& Hirata Y. Defective expression of prohormoneconvertase $1 / 3$ insilentcorticotroph adenoma. Endocrine Journal 200754 777-782. (https://doi.org/10.1507/endocrj.K07-059)

16 Nagaya T, Seo H, Kuwayama A, Sakurai T,Tsukamoto N, Nakane T, Sugita K \& Matsui N. Proopiomelanocortin gene expression in silent corticotroph-cell adenoma and Cushing's disease. Journal of Neurosurgery 199072 262-267. (https://doi.org/10.3171/ ins.1990.72.2.0262)

17 Matsuno A, Okazaki R, Oki Y \& Nagashima T. Secretion of highmolecular-weight adrenocorticotropic hormone from a pituitary adenoma in a patient without Cushing stigmata. Case report. Journal of Neurosurgery 2004101 874-877. (https://doi.org/10.3171/ jns.2004.101.5.0874)

18 Kim D, Ku CR, Park SH, Moon JH, Kim EH, Kim SH \& Lee EJ. Clinical parameters to distinguish silent corticotroph adenomas from other nonfunctioning pituitary adenomas. World Neurosurgery $2018 \mathbf{1 1 5}$ e464-e471. (https://doi.org/10.1016/j.wneu.2018.04.070)

19 Righi A, Faustini-Fustini M, Morandi L, Monti V, Asioli S, Mazzatenta D, Bacci A \& Foschini MP. The changing faces of corticotroph cell adenomas: the role of prohormone convertase $1 / 3$. Endocrine 201756 286-297. (https://doi.org/10.1007/s12020-0161028-0)

20 Raverot G, Wierinckx A, Jouanneau E, Auger C, Borson-Chazot F, Lachuer J, Pugeat M \& Trouillas J. Clinical, hormonal and molecular characterization of pituitary ACTH adenomas without (silent corticotroph adenomas) and with Cushing's disease. European Journal of Endocrinology 2010163 35-43. (https://doi.org/10.1530/EJE-100076)

21 Cooper O, Ben-Shlomo A, Bonert V, Bannykh S, Mirocha J \& Melmed S. Silent corticogonadotrophadenomas: clinical and cellular 
characteristics and longterm outcomes. Hormones and Cancer 20101 80-92. (https://doi.org/10.1007/s12672-010-0014-x)

22 Webb KM, Laurent JJ, Okonkwo DO, Lopes MB, Vance ML \& Laws Jr ER. Clinical characteristics of silent corticotrophic adenomas and creation of an internet-accessible database to facilitate their multiinstitutional study. Neurosurgery 200353 1076-1084; discussion 1084. (https://doi.org/10.1227/01.neu.0000088660.16904.f7)

23 Turner HE, Stratton IM, Byrne JV, Adams CB \& Wass JA. Audit of selected patients with nonfunctioning pituitary adenomas treated without irradiation - a follow-up study. Clinical Endocrinology 1999 51 281-284. (https://doi.org/10.1046/j.1365-2265.1999.00865.x)

24 Dekkers OM, Pereira AM, Roelfsema F, Voormolen JH, Neelis KJ, Schroijen MA, Smit JW \& Romijn JA. Observation alone after transsphenoidal surgery for nonfunctioning pituitary macroadenoma. Journal of Clinical Endocrinology and Metabolism 2006 91 1796-1801. (https://doi.org/10.1210/jc.2005-2552)

25 Brochier S, Galland F, Kujas M, Parker F, Gaillard S, Raftopoulos C, Young J, Alexopoulou O, Maiter D \& Chanson P. Factors predicting relapse of nonfunctioning pituitary macroadenomas after neurosurgery: a study of 142 patients. European Journal of Endocrinology 2010163 193-200. (https://doi.org/10.1530/EJE-100255)
26 Sheehan JP, Xu Z \& Lobo MJ. External beam radiation therapy and stereotactic radiosurgery for pituitary adenomas. Neurosurgery Clinics of North America 201223 571-586. (https://doi.org/10.1016/j. nec.2012.06.011)

$27 \mathrm{Xu}$ Z, Ellis S, Lee CC, Starke RM, Schlesinger D, Lee Vance M, Lopes MB \& Sheehan J. Silent corticotroph adenomas after stereotactic radiosurgery: a case-control study. International Journal of Radiation Oncology, Biology, Physics 201490 903-910. (https://doi. org/10.1016/j.ijrobp.2014.07.013)

28 Fang H, Tian R, Wu H, Xu J, Fan H, Zhou J \& Zhong L. Cushing disease after treatment of nonfunctional pituitary adenoma: a case report and literature review. Medicine 201594 e2134. (https://doi. org/10.1097/MD.0000000000002134)

29 Alahmadi H, Lee D, Wilson JR, Hayhurst C, Mete O, Gentili F, Asa SL $\&$ Zadeh G. Clinical features of silent corticotroph adenomas. Acta Neurochirurgica 2012154 1493-1498. (https://doi.org/10.1007/ s00701-012-1378-1)

30 Salehi F, Scheithauer BW, Kovacs K, Horvath E, Syro LV,Sharma S, Manoranjan B \& Cusimano M. O-6-methylguanine-DNA methyltransferase (MGMT) immunohistochemical expression in pituitary corticotroph adenomas. Neurosurgery 201270 491-496; discussion 496. (https://doi.org/10.1227/NEU.0b013e318230ac63)

Received in final form 19 August 2019

Accepted 20 August 2019 